\title{
CAPIM-ELEFANTE ENSILADO COM A PLANTA INTEIRA DE SOJA E FUBÁ
}

Vinicius Lelis Ferreira ${ }^{1}$, Hélio Henrique Vilela ${ }^{2}$, Regina Kitagawa Grizotto ${ }^{3}$, Nathália Gonçalves de Jesus ${ }^{4}$, Jéssyca Caroline de Faria ${ }^{4}$, Larissa de Melo Coelho ${ }^{4}$, Adriane Aparecida Galvão Ferreira ${ }^{4}$

\begin{abstract}
RESUMO - O capim-elefante é uma gramínea tropical com alto potencial para produção de forragem e pode ser utilizada para ensilagem. No entanto, quando ensilado no momento ideal, apresenta-se com baixo teor de MS, o que pode causar fermentações indesejáveis. Nesse sentido, o objetivo desse trabalho foi avaliar os efeitos da adição de fubá e planta inteira de soja sobre a qualidade bromatológica da silagem de capim-elefante. Para isso, utilizou-se um delineamento experimental inteiramente casualizado, com quatro tratamentos: ensilagem de soja colhida no estádio $\mathrm{R}_{6}$, ensilagem do capim-elefante $+10 \%$ de fubá, ensilagem usando $75 \%$ de capimelefante $+25 \%$ de soja $+10 \%$ de fubá e ensilagem usando $50 \%$ de capim-elefante $+50 \%$ de soja +10 $\%$ de fubá, com cinco repetições. Os dados foram submetidos à análise de variância e as médias dos tratamentos comparadas pelo teste Tukey a $5 \%$ de significância. O uso de fubá e soja foi eficiente na redução dos valores de $\mathrm{pH}$ das silagens, os quais variaram de 3,49 a 6,12 nas silagens de capim-elefante acrescido de fubá e silagem exclusiva de soja, respectivamente; bem como no aumento da MS das silagens, a qual variou de $27,05 \%$ a $30,18 \%$ para as silagens de capim $+10 \%$ de fubá e as de soja, respectivamente. A adição de soja na ensilagem de capim-elefante elevou os teores de PB nas silagens e aquelas confeccionadas apenas com capim e fubá foram as que apresentaram maiores teores de $\operatorname{FDN}(57,36 \%)$ e lignina (12,16 \%). A adição simultânea da planta inteira de soja colhida no estádio $\mathrm{R}_{6}$ e fubá na ensilagem do capim-elefante produz silagens com parâmetros indicativos de melhor valor nutritivo.
\end{abstract}

Palavras chave: gramínea, Pennisetum purpureum, silagem.

\section{ELEPHANT GRASS ENSILED WITH WHOLE SOY PLANTAND CORN MEAL}

\begin{abstract}
The elephant grass is a tropical grass with high potential for forage production and can be used for silage. However, when ensiled at the right time, it presents with low DM content, which can cause undesirable fermentations. In this sense, the objective of this study was to evaluate the effects of the addition of corn meal and whole soybean plant on chemical quality of silage of elephant grass. For this, we used a completely randomized design with four treatments: soybean silage harvested at the R6 stage, silage of elephant grass $+10 \%$ corn meal, silage using $75 \%$ of elephant grass $+25 \%$ soybean $+10 \%$ of corn meal and silage using $50 \%$ of elephant grass $+50 \%$ soybean $+10 \%$ of corn meal, with five repetitions. Data were subjected to analysis of variance and treatment means were compared by Tukey test at $5 \%$ significance. The use of corn meal and soybean was effective in reducing the pH of silage, which ranged from 3.49 at 6.12 in the elephant grass silage with corn meal and soybean silages, respectively; as well as in increasing the DM of the silage, which ranged from $27.05 \%$ to $30.18 \%$ for elephant grass silage $+10 \%$ of corn meal and soybean, respectively. The addition of soy in elephant grass silage increased the CP content in silage and those made only with grass and corn showed the highest NDF values (57.36\%) and lignin (12.16 $\%)$. The simultaneous addition of whole soybean plant collected in the $R_{6}$ stage and cornmeal in the elephant grass silage produced silages with parameters indicative of better nutritional value.
\end{abstract}

Keywords: grass, Pennisetum purpureum, silage.

\footnotetext{
${ }^{1}$ Professor do Centro Universitário de Patos de Minas - UNIPAM. heliohv@unipam.edu.br

${ }^{2}$ Aluno do Curso de Agronomia - Centro Universitário de Patos de Minas - UNIPAM.

${ }^{3}$ Pesquisador Científico da Agência Paulista de Tecnologia dos Agronegócios.

${ }^{4}$ Aluna do Curso de Zootecnia - Centro Universitário de Patos de Minas - UNIPAM.
} 


\section{INTRODUÇÃO}

O uso de silagens feitas com gramíneas forrageiras tropicais tem se apresentado há, no mínimo, duas décadas, como uma opção interessante para a alimentação de ruminantes, já que o período mais seco do ano compreende uma época onde ocorre escassez de volumoso, principal alimento desses animais. Dentre as gramíneas tropicais, tem-se o capim-elefante, gramínea perene que comumente é utilizada na forma de capineiras para corte e fornecimento do capim picado aos animais. No entanto, também pode ser utilizada para ensilagem, principalmente devido à alta capacidade de produzir matéria seca, de bom valor nutritivo (Andrade \& Lavezzo, 1998). Com base nas informações que se tem a respeito da associação entre a produção forrageira e o seu valor nutritivo, alturas de 1,60 a $1,85 \mathrm{~m}$ e/ou idades de 56 a 80 dias são apontadas como adequadas para o corte do capimelefante para ensilagem (Vilela, 1998).

Entretanto, algumas características das gramíneas, especialmente do capim-elefante, devem ser levadas em consideração no momento do corte para a produção de silagem, entre elas, a baixa concentração de carboidratos solúveis, alta umidade e alta capacidade tampão (McDonald, 1981). Vale ressaltar que essas características influenciam negativamente a fermentação, impedindo o rápido decréscimo do $\mathrm{pH}$, permitindo as fermentações secundárias indesejáveis e, consequentemente, prejudicando a qualidade da silagem (McDonald, 1981; Lavezzo, 1993). Isso acontece porque no período ideal para ensilagem do capim-elefante, a alta umidade encontrada ( $80 \%$ ou mais), possibilita a ação de microrganismos indesejáveis durante a fermentação (Wilkinson, 1983).

Nesse sentido, algumas técnicas têm sido usadas com objetivo de aumentar o teor de matéria seca e a quantidade de carboidratos solúveis do capim-elefante na ensilagem. Exemplos dessas técnicas são o emurchecimento do capim e a utilização de aditivos (Tosi et al., 1999), principalmente os sequestrantes de umidade. Porém, além de aumentar os gastos com mão-de-obra, a perda de umidade por exposição ao sol (emurchecimento) não é completamente satisfatória, tendo em vista que o diâmetro dos colmos do capimelefante torna difícil o transporte de água do interior para as bordas destes (Tosi et al., 1999). Além disso, durante o emurchecimento do capim, ocorrem perdas devido ao processo respiratório e atividades proteolíticas da planta, resultando na diminuição de substratos e acréscimo do nitrogênio não proteico (McDonald, 1981).

Para elevar o teor de matéria seca (MS) do material a ser ensilado e, consequentemente, melhorar a qualidade da silagem e a fermentação, é possível utilizar aditivos sequestrantes de umidade (e. g. fubá de milho), reduzindo os decréscimos de nutrientes e MS em decorrência do aumento de efluentes (Wilkinson, 1983).

Por possuir alto valor nutricional, elevada produção de matéria seca e facilidade de colheita mecânica, a ensilagem de soja vem crescendo nos últimos anos. Melo Filho et al. (2006) em estudo conduzido em Viçosa, MG, envolvendo 20 variedades e 2 linhagens, registraram produções de matéria seca variando de 5,38 a 11,78 $\mathrm{t} \mathrm{ha}^{-1}$. Adicionalmente, o uso de silagem de leguminosa apresenta-se como opção, por aumentar o teor proteico da dieta, além de supri-la com maior quantidade de cálcio e fósforo, reduzindo assim, o custo de produção, através da menor necessidade de suplementação com concentrado proteico (Baxter et al., 1984) e, quando colhida no estádio $\mathrm{R}_{6}$, geralmente possui teor de matéria seca favorável à fermentação, alto teor de proteína bruta (PB) e alta digestibilidade (Muñoz et al, 1983), associada à maior aceitabilidade da silagem pelos animais (Coffey et al., 1995).

Nesse sentido, buscando alternativas que melhorem a fermentação e a qualidade da silagem de capim-elefante, este trabalho teve por objetivo avaliar a qualidade bromatológica da silagem de capim-elefante aditivada com fubá e a planta inteira de soja.

\section{MATERIAL E MÉTODOS}

O trabalho foi desenvolvido nas dependências da Escola Agrotécnica Afonso Queiroz - Campus II do Centro Universitário de Patos de Minas (UNIPAM) e no Laboratório de Nutrição e Análise de Alimentos do UNIPAM, ambos situados em Patos de Minas, MG. O objetivo foi avaliar a qualidade bromatológica da silagem de capim-elefante aditivada com fubá e a planta inteira de soja, colhida e picada no estádio fenológico $\mathrm{R}_{6}$, segundo escala de Fehr \& Caviness (1977), ou seja, com os grãos cheios ou completos, porém ainda verdes. Para isso, utilizou-se um delineamento inteiramente casualizado, com quatro tratamentos e cinco repetições. Os tratamentos utilizados foram os seguintes: ensilagem da planta inteira de soja colhida no estádio fenológico $\mathrm{R}_{6}\left(\right.$ Soja $\left.\mathrm{R}_{6}\right)$, ensilagem de capim-elefante $+10 \%$ de 
fubá (CE 10F), ensilagem usando $75 \%$ de capim-elefante $+25 \%$ de planta inteira de soja colhida no estádio fenológico $\mathrm{R}_{6}+10 \%$ de fubá (75CE25S10F) e ensilagem usando $50 \%$ de capim-elefante $+50 \%$ de planta inteira de soja colhida no estádio fenológico $\mathrm{R}_{6}+10 \%$ de fubá (50CE50S10F).

O capim-elefante (Pennisetum purpureum Schum cv. Napier) foi colhido manualmente, rente ao solo, na Escola Agrotécnica Afonso Queiroz, quando apresentava altura aproximada de $1,20 \mathrm{~m}$ e picado em partículas de 2 a $3 \mathrm{~cm}$, em picadora estacionária de forragem. Quanto à soja, foi utilizada a variedade $\mathrm{N}$ $7255 \mathrm{rr}$, semeada no dia 12/01/2014, adubada no plantio com $350 \mathrm{~kg} / \mathrm{ha}$ de 8-28-16 e colhida manualmente, rente ao solo, no dia 03/05/14; portanto com 111 dias após a semeadura, quando atingiu o estádio fenológico $\mathrm{R}_{6}$, a qual também foi picada em picadora estacionária de forragem.

Depois da colheita e picagem das plantas, realizouse a pesagem do material picado e determinou-se a quantidade de capim, de soja e fubá que foram misturados na ensilagem. Após a mistura e homogeneização da massa de forragem, ela foi ensilada em silos feitos de canos de PVC, no dia 03 de maio de 2014, compactados manualmente, com auxilio de bastões de madeira e fechados com tampas dotadas de válvula tipo "Bünsen". Os silos permaneceram fechados por 47 dias e foram então abertos para avaliação das silagens, as quais foram analisadas no Laboratório de Nutrição e Análise de Alimentos do Centro Universitário de Patos de Minas - UNIPAM.

No momento em que os silos foram abertos, o $\mathrm{pH}$ foi avaliado utilizando-se um potenciômetro Beckman Expandomatic SS-2, segundo o método descrito por Silva \& Queirroz (2002). A porcentagem de MS da forragem e das silagens foi determinada segundo metodologia da AACC (1976). O teor de nitrogênio foi determinado utilizando-se o aparelho de destilação a vapor microKjedahl, conforme a AOAC (1997) e o teor de PB calculado utilizando-se o fator de conversão 6,25. As porcentagens de fibra insolúvel em detergente neutro (FDN), fibra insolúvel em detergente ácido (FDA) e lignina (LIG) foram obtidas segundo metodologia proposta por Van Soest et al. (1991). O percentual de extrato etéreo (EE) foi determinado segundo metodologia descrita em Silva \& Queiroz (2002). A porcentagem de hemicelulose foi determinada subtraindo-se do valor de FDN, a porcentagem de FDA e, a porcentagem de celulose, subtraindo da FDA, a porcentagem de lignina. A determinação da digestibilidade verdadeira da MS (\% DIVMS) foi realizada no laboratório de Análise de Alimentos da Agência Paulista de Tecnologia do Agronegócio (Apta - Colina/SP), conforme metodologia de Goering \& Van Soest (1970).

Os dados obtidos foram submetidos à análise de variância e as medias comparadas pelo teste Tukey a $5 \%$ de significância, utilizando-se o software computacional Análise de Variância para Dados Balanceados - SISVAR (Ferreira, 2014).

\section{RESULTADOS E DISCUSSÃO}

Na Tabela 1 são apresentadas as médias de $\mathrm{pH}$ e das porcentagens de MS, PB e EE com seus respectivos coeficientes de variação (CV\%). Observa-se que o $\mathrm{pH}$ e as porcentagens de MS, PB e EE foram influenciadas pelos tratamentos $(\mathrm{P}<0,05)$.

$\mathrm{O}$ pH médio da silagem de soja mostrou-se mais elevado que nas demais silagens. Segundo Mello Filho (2006), as silagens de leguminosas em geral se estabilizam com valores de $\mathrm{pH}$ mais elevados e vários fatores contribuem para que isso aconteça. Este $\mathrm{pH}$ mais alto pode ocorrer devido as leguminosas apresentarem elevado poder tampão (Pereira et al., 2009), sendo promovido por aminoácidos residuais e presença de cátions como $\mathrm{K}^{+}, \mathrm{Ca}^{2+} \mathrm{e} \mathrm{Mg}^{2+}$, que neutralizam os ácidos orgânicos produzidos pela fermentação, dificultando a queda do pH (Lima, 1992).

Além disso, o maior valor de $\mathrm{pH}$ na silagem exclusiva de soja pode estar relacionado ao seu maior valor proteico (Tabela 1), resultando em redução na relação carboidratos:proteína, que, conforme Van Soest (1994), é importante influenciadora do $\mathrm{pH}$ da silagem. Essa influencia ocorre, pois aminoácidos básicos, aminas e amônia, produtos finais da degradação da proteína durante a fermentação, impedem a rápida queda do pH da massa ensilada (McKersie, 1985).

Adicionalmente, a soja possui baixa população autóctone de bactérias produtoras do ácido lático (Pereira et al., 2007) e quando colhida no estádio $\mathrm{R}_{6}$, possui conteúdo de carboidratos solúveis abaixo do requerido para adequada fermentação (Blount et al., 2017), o que foi constatado por Melo Filho (2006), os quais encontraram valores de 2,3 a $6,6 \%$ para carboidratos solúveis nas silagens de soja colhidas no estádio $\mathrm{R}_{6}$. 
Tabela 1 - Potencial hidrogeniônico $(\mathrm{pH})$ e porcentagens de MS, PB e EE de silagens de soja, de capim-elefante com fubá e de silagens de capim-elefante com soja e fubá

\begin{tabular}{lccrr}
\hline \multirow{2}{*}{ Tratamentos } & \multicolumn{3}{c}{ Variáveis } \\
\cline { 2 - 5 } & $\mathrm{pH}$ & $\% \mathrm{MS}$ & $\% \mathrm{~PB}$ & \\
\hline${ }^{1}$ Soja R & $6,12 \mathrm{~A}$ & $30,18 \mathrm{~A}$ & $20,81 \mathrm{~A}$ & $11,63 \mathrm{~A}$ \\
${ }^{2} \mathrm{CE} \mathrm{10F}$ & $3,49 \mathrm{D}$ & $27,05 \mathrm{C}$ & $9,37 \mathrm{~B}$ & $3,17 \mathrm{C}$ \\
${ }^{3} 75 \mathrm{CE} 25 \mathrm{~S} 10 \mathrm{~F}$ & $3,62 \mathrm{C}$ & $27,77 \mathrm{BC}$ & $12,39 \mathrm{~B}$ & $3,58 \mathrm{C}$ \\
${ }^{4} 50 \mathrm{CE} 50 \mathrm{~S} 10 \mathrm{~F}$ & $3,75 \mathrm{~B}$ & $30,00 \mathrm{AB}$ & $13,49 \mathrm{~B}$ & $5,48 \mathrm{~B}$ \\
Média & 4,25 & 28,75 & 14,01 & 5,97 \\
CV $(\%)$ & 1,45 & 4,38 & 26,72 & 11,54 \\
\hline
\end{tabular}

Letras iguais na coluna não diferem entre si pelo teste de Tukey a $5 \%$ de probabilidade. ${ }^{1}$ Silagem de soja ensilada no estádio R6; ${ }^{2}$ Silagem de capim-elefante aditivada com $10 \%$ de fubá; ${ }^{3}$ Silagem confeccionada com $75 \%$ de capim-elefante, $25 \%$ de soja e $10 \%$ de fubá; ${ }^{4}$ Silagem confeccionada com $50 \%$ de capim-elefante, $50 \%$ de soja e $10 \%$ de fubá.

Com baixo teor de carboidratos solúveis, falta substrato para o desenvolvimento de bactérias láticas e, consequentemente, a produção de ácido lático é menor, não sendo suficiente para reduzir o $\mathrm{pH}$ a valores inferiores a 4,2 .

Sendo o pH utilizado como um parâmetro de avaliação do processo fermentativo da silagem e considerando o teor de MS da silagem de soja, é possível inferir que a fermentação dessa silagem não foi adequada, o que possivelmente também aconteceu no experimento de Dias et al. (2010), os quais encontraram $\mathrm{pH}$ de 5,3 nas silagens de soja colhida no estádio $\mathrm{R}_{6}$. Já a mistura de capim-elefante e fubá na ensilagem da soja foi eficiente na redução dos valores de $\mathrm{pH}$, ficando abaixo de 4,2, valor este considerado adequado para o controle de fermentações indesejáveis. Rigueira et al. (2015) também observaram redução nos valores de $\mathrm{pH}$ quando se adicionou melaço em pó e/ou melaço em pó mais aditivo biológico nas silagens de soja em comparação à silagem exclusiva de soja.

Segundo Van Soest (1994) e Pesce et al. (2000), o teor ideal de MS para ensilagem varia entre 30 e 35\%, evitando perdas de nutrientes devido a formação de efluentes, bem como a ocorrência de processos biológicos que produzam gases, água e calor. Adicionalmente, segundo estes autores, este teor de MS proporciona uma fermentação láctica adequada para a manutenção do valor nutritivo da silagem. Ao contrário, o excesso de umidade na forragem ensilada implica em riscos de fermentações secundárias indesejáveis, já que a menor pressão osmótica favorece o desenvolvimento das bactérias do gênero Clostridium sp. (Wilkinson, 1983).
Considerando esses valores pode-se observar que somente as silagens de soja e as de capim confeccionadas com $50 \%$ de soja e $10 \%$ de fubá obtiveram valores de MS desejáveis para ocorrência de uma boa fermentação. De forma indireta, pode-se observar que a soja possuía um teor de MS mais elevado em comparação ao capim-elefante, quando ensilada, visto que sua silagem apresentou teores de MS mais elevados. Por possuir maior teor de MS, a adição de $50 \%$ de soja mais $10 \%$ de fubá, foram fatores determinantes para o aumento no teor de MS da silagem com maior adição de soja. Melo Filho (2006), analisando variedades de soja para silagem, encontraram valores de $21,7 \%$ a $29,1 \%$ de MS em variedades de soja para silagem colhidas no estádio $\mathrm{R}_{6}$, valores inferiores ao encontrado para as silagens de soja produzidas neste experimento. Por outro lado, Dias et al. (2010) encontram valores de MS iguais a 36,29\% e 27,01\% nas silagens de soja colhida no estádio $\mathrm{R}_{6}$, nos anos de 2005 e 2006, respectivamente.

Em relação à $\mathrm{PB}$, as silagens de soja foram as que apresentaram maior valor $(20,81 \%)$, muito próximo ao encontrado por Rigueira et al. (2015), os quais registraram valor de $20,10 \%$ de $\mathrm{PB}$ nas silagens de soja colhida no estádio $\mathrm{R}_{6}$ e superior ao que foi observado por Dias et al. (2010), os quais registraram $14,91 \%$ e $12,76 \%$ de PB nas silagens de soja colhida no estádio $\mathrm{R}_{6}$, nos anos de 2005 e 2006 , respectivamente. A soja, sendo uma leguminosa, possui naturalmente maior teor de PB e, no estádio em que foi colhida, com os grãos já formados, possivelmente, eles tenham contribuído para que estes valores fossem mais elevados. Embora não tenha ocorrido diferença 
estatística entre as silagens produzidas apenas com capim e fubá e aquelas onde se adicionou a soja, biologicamente, na produção animal o aumento da PB nas silagens confeccionadas com soja pode fazer diferença.

Quanto ao EE, as silagens de soja, por já conterem grãos que são oleaginosos, foram as que apresentaram maior porcentagem de EE, superior ao encontrado por Rigueira et al. (2015), os quais registraram 9,0\% de EE nas silagens de soja colhida no estádio $\mathrm{R}_{6}$. Já as silagens apenas de capim e fubá e aquelas com $75 \%$ de capim $+25 \%$ de soja $+10 \%$ de fubá foram as que apresentaram menores porcentagens de EE, uma vez que foram confeccionadas com maior participação de alimentos pobres em EE.

Vale ressaltar que a recomendação de gordura na dieta de bovinos leiteiros, feita pelo NRC (2001), é de no máximo 6 a $7 \%$ na MS. Nesse sentido, o uso exclusivo de silagem de soja não deve ser recomendando, pois pode acarretar em reduções na fermentação ruminal, na digestibilidade da fibra e na taxa de passagem.

A fração fibrosa das silagens, com exceção da porcentagem de FDA e celulose, foi influenciada pelos tratamentos $(\mathrm{P}<0,05)$, conforme se observa na Tabela 2.

As silagens de soja foram as que apresentaram menor porcentagem de FDN, inferior aos $52,77 \%$ e $52,52 \%$ de FDN observados nos trabalhos de Dias et al. (2010) e Rigueira et al. (2015), respectivamente.

Verificou-se que a silagem de capim-elefante aditivada apenas com fubá apresentou os maiores teores de FDN e LIG. Gramíneas, especialmente as de clima tropical, geralmente apresentam maiores teores de fibra quando comparadas às leguminosas, ou seja, possuem maior conteúdo de parede celular. Isso ocorre devido à natureza anatômica das gramíneas $\mathrm{C}_{4}$, as quais possuem alta proporção de tecido vascular(Van Soest, 1994), o que explica a grande diferença entre os valores de FDN observado entre as silagens de soja e de capim com fubá.

Existem correlações entre a ingestão voluntária e a FDN, graças à relação desta com a ocupação de espaço pelos volumosos (Mertens, 1982). Assim, se a ingestão é limitada pela ocupação de espaço do trato gastrintestinal, alimentos com alto teor de FDN terão sua ingestão restringida (Araújo et al., 1998) e, segundo Van Soest (1994), teores de FDN acima de 55 \% são limitantes à ingestão do alimento. Nesse sentido, podese dizer que haveria restrição de consumo apenas na silagem de capim com fubá.

Segundo Silva (1981), a hemicelulose inclui polímeros de pentoses e certos polímeros de hexose e ácidos urônicos, mostrando-se mais digerível que a celulose. Nesse sentido, provavelmente as silagens somente de capim e aquelas que continham capim seriam as de melhor digestibilidade. No entanto, a digestibilidade dos alimentos para os ruminantes depende da proporção e digestibilidade dos componentes da parede celular. Quando esta proporção ou o grau de lignificação aumenta, ocorre redução na digestibilidade do alimento (Ellis, 1969), o que pode ser verificado neste trabalho, uma vez que a digestibilidade foi menor justamente nas silagens apenas de capim e fubá, as quais apresentaram maior teor de lignina.

Os teores de FDA não foram influenciados pelos tratamentos $(\mathrm{P}>0,05)$ e variaram de $30,58 \%$ a $36,87 \%$

Tabela 2 - Porcentagens de FDN, lignina (LIG) e hemicelulose (HEMIC) de silagens de soja, de capim-elefante com fubá e de silagens de capim-elefante com soja e fubá

\begin{tabular}{|c|c|c|c|c|}
\hline \multirow{2}{*}{ Tratamentos } & \multicolumn{4}{|c|}{ Variáveis } \\
\hline & $\% \mathrm{FDN}$ & $\% \mathrm{LIG}$ & $\%$ HEMIC & $\%$ DIVMS \\
\hline${ }^{1}$ Soja $\mathrm{R}_{6}$ & $41,73 \mathrm{C}$ & $5,80 \mathrm{~B}$ & $9,30 \mathrm{~B}$ & $75,80 \mathrm{~A}$ \\
\hline${ }^{2} \mathrm{CE} 10 \mathrm{~F}$ & $57,36 \mathrm{~A}$ & $12,17 \mathrm{~A}$ & $20,48 \mathrm{~A}$ & $71,00 \mathrm{~B}$ \\
\hline${ }^{3} 75 \mathrm{CE} 25 \mathrm{~S} 10 \mathrm{~F}$ & 49,44 B & $8,37 \mathrm{AB}$ & $18,46 \mathrm{~A}$ & $74,40 \mathrm{~A}$ \\
\hline${ }^{4} 50 \mathrm{CE} 50 \mathrm{~S} 10 \mathrm{~F}$ & $47,00 \mathrm{BC}$ & $6,95 \mathrm{~A}$ & $16,42 \mathrm{~A}$ & $76,00 \mathrm{~A}$ \\
\hline Média & 48,88 & 8,32 & 16,16 & 74,30 \\
\hline $\mathrm{CV}(\%)$ & 6,33 & 27,78 & 15,26 & 1,35 \\
\hline
\end{tabular}

Letras iguais na coluna não diferem entre si pelo teste de Tukey a $5 \%$ de probabilidade. ${ }^{1}$ Silagem de soja ensilada no estádio R6; ${ }^{2}$ Silagem de capim-elefante aditivada com $10 \%$ de fubá; ${ }^{3}$ Silagem confeccionada com $75 \%$ de capim-elefante, $25 \%$ de soja e $10 \%$ de fubá; ${ }^{4}$ Silagem confeccionada com $50 \%$ de capim-elefante, $50 \%$ de soja e $10 \%$ de fubá. 
para as silagens confeccionadas com $50 \%$ de capim $+50 \%$ de soja $+10 \%$ de fubá e para aquelas somente de capim $+10 \%$ de fubá, respectivamente. Igualmente, a porcentagem de celulose também não sofreu efeito dos tratamentos $(\mathrm{P}>0,5)$, variando de $22,61 \%$ nas silagens com $75 \%$ de capim $+50 \%$ de soja $+10 \%$ de fubá a $26,63 \%$ nas silagens somente de soja.

\section{CONCLUSÃO}

A adição simultânea da planta inteira de soja colhida no estádio $\mathrm{R}_{6}$ e fubá na ensilagem do capim-elefante produz silagens com parâmetros indicativos de melhor valor nutritivo em relação à silagem exclusiva de capimelefante aditiva com fubá.

\section{LITERATURA CITADA}

\section{AACC - AMERICAN ASSOCIATION OF CEREAL CHEMISTS. Approved methods of the American Association of Cereal Chemists. 7.ed. St. Paul: 1976. 256p.}

ANDRADE, J.B.; LAVEZZO, W. Aditivos na ensilagem do capim-elefante. I. Composição bromatológica das forragens e das respectivas silagens. Pesquisa Agropecuária Brasileira, v.33, n.11, p.1859-1872, 1998.

AOAC - ASSOCIATION OF OFFICIAL ANALYTICAL CHEMISTS. Official methods of analysis. 16.ed. Gaithersburg: AOAC International, 1997.

ARAÚJO, G.G.L.; SILVA, J.F.C.; VALADARES

FILHO, S.C. et al. Consumo e digestibilidade total dos nutrientes de dietas contendo diferentes níveis de volumoso, em bezerros. Revista Brasileira de Zootecnia, v.27, n.2, p.345354, 1998.

BAXTER, H.D.; MONTGOMERY, M.J.; OWEN, J.R. Comparison of soybean-grain sorghum silage with corn silage for lactating cows. Journal Dairy Science, v.67, n.1, p.88-96, 1984.

BLOUNT, A.R.S.; WRIGHT, D.L.; SPRENKEL, R.K. et al. Forage soybeans for grazing, hay and silage. Agronomy Department, Florida Cooperative Extension Service, Institute of Food and Agricultural Sciences, University of Florida. Revised January 2017. Disponível em: http: <http:/ /www.edis.ifas.ufl.edu> Acesso em: 28/03/2017.
COFFEY, K.P.; GRANADE, G.V.; MOYER, J.L. In vitro digestibility and preference by sheep for silages made from whole-plant soybeans. The Professional Animal Scientist, v.11, p.8187, 1995.

DIAS, F.J.; JOBIM, C.C.; SORIANI FILHO, J.L. et al. Composição química e perdas totais de matéria seca na silagem de planta de soja. Acta

Scientiarum Animal Sciences, Maringá, v.32, n.1, p.19-26, 2010.

ELLIS, W.C. Chemical methods for assessing the nutritive value of forages. Texas: Department of Animal Science, Texas University, 1969.

FEHR, W.R.; CAVINESS, C.E. Stages of soybean development. Special report 80 . Ames, Iowa: Cooperative Extension Service, Iowa State University, 1977. 11p.

FERREIRA, D.F. Sisvar: a Guide for its Bootstrap procedures in multiple comparisons. Ciência e Agrotecnologia, v.38, n.2, p.109-112, 2014.

GOERING, H.K.; VAN SOEST, P.J. Forage fiber analysis (Apparatus, reagents, procedures and some applications). Washington, DC: USDA, 1970 (Agricultural Handbook, 379).

LAVEZZO, W. Ensilagem do capim-elefante. In: SIMPÓSIO SOBRE MANEJO DA PASTAGEM, 10, 1993, Piracicaba. Anais... Piracicaba: Fundação de Estudos Agrários “Luis de Queiroz”, 1993. p.169-276.

LIMA, G.F.C. Ensilagem. In: RESERVAS ESTRATÉGICAS DE FORRAGEM: UMA ALTERNATIVA PARA MELHORAR A CONVIVÊNCIA DOS REBANHOS FAMILIARES COM A SECA. (Série Circuito de Tecnologias para a Agricultura Familiar). Natal, RN: EMPARN, 1992. p.62-74.

McDONALD, P. The biochemistry of silage. New York: John Wiley \& Sons, 1981. 207p.

McKERSIE, B.D. Effect of $\mathrm{pH}$ on proteolysis in ensiled legume forage. Agronomy Journal, v.77, n.1, p.81-86, 1985 . 
MELO FILHO, O.L. Avaliação de variedades e progênies de soja para produção de silagem. Viçosa, MG: UFV, 2006. 84p. Tese (Doutorado em Genética e Melhoramento) - Universidade Federal de Viçosa, 2006.

MERTENS, D.R. Using neutral detergent fiber to formulate dairy rations. In: PROC. GA. NUT. CONF. FOR THE FEED INDUSTRY. Athens: University Georgia, 1982. p.116-126.

MUÑOZ, A.; HOLT, E.; WEAVER, R. Yield and quality of soybean hay as influenced by stage of growth and plant density. Agronomy

Journal, v.75, p.147-149, 1983.

NATIONAL RESEARCH COUNCIL - NRC. Nutrient requirements of dairy cattle. 7.ed. Washington, D.C.: National Academy Press, 2001.450p.

PEREIRA, O.G.; SANTOS, E.M.; ROSA, L.O.; MELLO FILHO, O.L. Populações microbianas em silagens de três variedades de soja, tratadas com inoculante microbiano. In: REUNIÃO ANUAL DA SOCIEDADE BRASILEIRA DE ZOOTECNIA, 2007, Jaboticabal. Anais...Jaboticabal (CD-ROOM).

PEREIRA, O.G.; OLIVEIRA, A.S.; RIBEIRO, K.G. Strategies to enable the use of legume silage in ruminant production. In: INTERNATIONAL SYMPOSIUM ON FORAGE QUALITY AND CONSERVATION, 2009, São Paulo.

Proceedings... Piracicaba: Fealq, 2009. p.109136.

PESCE, D.M.C.; GONÇALVES, L.C.; RODRIGUEZ, N.M. Porcentagem, perda e digestibilidade in vitro da matéria seca das silagens de 20 genótipos de sorgo. Arquivo Brasileiro de Medicina Veterinária e Zootecnia, v.52, n.3, p.250-255, 2000.
RIGUEIRA, J.P.S.; PEREIRA, O.G.;

VALADARES FILHO, S.C. et al. Soybean silage in the diet for beef cattle. Acta

Scientiarum. Animal

Sciences, v.37, n.1, p.61-65, 2015.

SILVA, D.J. Análise de alimentos: métodos químicos e biológicos. Viçosa, MG: Editora UFV, 1981. 166p.

SILVA, D.J.; QUEIROZ, A.C. Análise de alimentos: métodos químicos e biológicos. 3.ed. Viçosa, MG: Editora UFV, 2002. 235p.

TOSI, P.; MATTOS, W.R.S.; TOSI, H. et al. Avaliação do capim-elefante (Pennisetum purpureum Scum.) cultivar Taiwan A-148, ensilado com diferentes técnicas de redução de umidade. Revista Brasileira de

Zootecnia, v.28, n.5, p.947-954, 1999.

VAN SOEST, P.J. Nutritional ecology of the ruminant. 2.ed. New York: Cornell University Press, 1994. 476p.

VAN SOEST, P.J.; ROBERTSON, J.B.; LEWIS, B.A. Methods for dietary fiber, neutral detergent fiber, and nonstarch polysaccharides in relation to animal nutrition. Journal of Dairy Science, v.74, n.10, p.3583-3597, 1991.

VILELA, D. Aditivos para silagens de plantas de clima tropical. In: SIMPÓSIO SOBRE ADITIVOS NA PRODUÇÃO DE RUMINANTES E NÃO RUMINANTES, 1998, Botucatu. Anais...Botucatu: SBZ, 1998. p.53-72.

WILKINSON, J.M. Silages made from tropical and temperate crops. 1 . The ensiling process and its influence on feed value. World Animal Review, v.45, n.45, p.36-42, 1983.

Recebido para publicação em 15/3/2017 e aprovado em 30/5/2017. 